Pesq. Vet. Bras. 30(1):37-41, janeiro 2010

\title{
Comparação entre diversos antígenos para o diagnóstico de Anaplasma marginale por ELISA ${ }^{1}$
}

\author{
Carlos A.N. Ramos ${ }^{2}$, Flábio R. Araújo ${ }^{3}$, Ingrid I.F. Souza ${ }^{3}$, Daniel S. Guedes \\ $\mathrm{Jr}^{4}$, Renato H.M. Oliveira ${ }^{3}$, Thaís A. Farias ${ }^{5}$, Jaqueline B. Oliveira ${ }^{6}$, Leucio C. \\ Alves $^{2}$ e Maria A.G. Faustino ${ }^{2}$
}

\begin{abstract}
Ramos C.A.N., Araújo F.R., Souza I.I.F., Guedes Jr D.S., Oliveira R.H.M., Farias T.A., Oliveira J.B., Alves L.C. \& Faustino M.A.G. 2010. [Comparison between several antigens for diagnosis of Anaplasma marginale by ELISA.] Comparação entre diversos antígenos para o diagnóstico de Anaplasma marginale por ELISA. Pesquisa Veterinária Brasileira 30(1):37-41. Laboratório de Doenças Parasitárias, Departamento de Medicina Veterinária, Universidade Federal Rural de Pernambuco, Recife, PE 52171900, Brazil. E-mail: carlosanramos@yahoo.com.br

Bovine anaplasmosis is a major disease in tropical and subtropical regions of the world by determine economical loss due mortality and productive reduction. The disease is caused by Anaplasma marginale, an intraerythrocytic rickettsia whose control requires, besides an efficient vaccine, the accurate identification of chronically infected cattle. Although the existence of diverse methods of diagnosis of this rickettsia, the serological methods, in particular the enzyme immunosorbent assays (ELISAs), are the most used due to its versatility and practice. However, due to the high number of antigens currently available, an evaluation becomes necessary to define which antigens present the better performance in the diagnosis of anaplasmosis. Sera from cattle positive or negative to $A$. marginale by PCR, and sera from cattle proceeding from Brazil and Costa Rica, were tested by ELISAs based in recombinant MSP1a, MSP2, and MSP5, a pool of the three recombinant proteins, and initial body lisate antigen $(\mathrm{Cl})$. Using sera from $A$. marginale positive cattle by PCR, the highest sensitivity was shown by CI ELISA. Nevertheless, the highest specificity, with sera from negative cattle by PCR, was shown by recombinants ELISAs. The percentiles of positive cattle from Brazil and Costa Rica were higher with $\mathrm{Cl}$ ELISA. Reasons for such differences were discussed.
\end{abstract}

INDEX TERMS: Anaplasma marginale, ELISA, recombinant proteins, antigens.

RESUMO.- Anaplasmose bovina é uma doença com grande importância nas regiões tropicais e subtropicais do mundo por determinar perdas econômicas devido à mor-

\footnotetext{
${ }^{1}$ Recebido em 3 de junho de 2009.

Aceito para publicação em 19 de agosto de 2009.

${ }^{2}$ Laboratório de Doenças Parasitárias, Departamento de Medicina Veterinária, Universidade Federal Rural de Pernambuco (UFRPE), Av. Dom Manoel de Medeiros s/n, Dois Irmãos, Recife, PE 52171-900, Brasil. *Autor para correspondência: carlosanramos@yahoo.com.br

${ }^{3}$ Embrapa Gado de Corte, Área de Sanidade Animal, BR262 Km 4, Cx. Postal 254, Campo Grande, MS 79002-970, Brasil.

${ }^{4}$ Universidade Federal Rural do Rio de Janeiro (UFRRJ), Seropédica, RJ 23890-000, Brasil.

${ }^{5}$ Universidade Federal de Mato Grosso do Sul (UFMS), Cidade Universitária, Cx. Postal 549, Campo Grande, MS 79070-900.

${ }^{6}$ Escola de Medicina Veterinária, Universidade Nacional Autônoma, Heredia, 86-3000, Costa Rica.
}

talidade e redução da produtividade. É causada por Anaplasma marginale, uma riquétsia intraeritrocítica obrigatória cujo controle requer, além de uma vacina eficiente, uma acurada identificação de bovinos cronicamente infectados. Apesar de existirem atualmente diversos métodos de diagnóstico dessa riquétsia, os métodos sorológicos, em particular o ensaio de imunoadsorção enzimáticaELISAs, são os mais utilizados devido à sua versatilidade e praticidade. No entanto, devido ao grande número de antígenos disponíveis, atualmente torna-se necessária uma avaliação para definir quais antígenos apresentam um melhor desempenho no diagnóstico da anaplasmose. Soros de bovinos positivos e negativos para $A$. marginale por PCR, e soros de animais provenientes do Brasil e Costa Rica, foram testados em ELISAs baseados em MSP1a, MSP2 e MSP5 recombinantes, um pool das três 
proteínas recombinantes, e antígeno de lisado de corpúsculos iniciais da riquétsia (Cl). Utilizando soro de bovinos positivos para $A$. marginale por PCR, uma maior sensibilidade foi observada no ELISA CI. No entanto, uma maior especificidade, com soro de bovinos negativos a PCR, foi observada com os ELISAs recombinantes. O porcentual de bovinos positivos do Brasil e Costa Rica foi maior com ELISA CI. Razões para essas diferenças são discutidas.

TERMOS DE INDEXAÇÃO: Anaplasma marginale, ELISA, proteínas recombinantes, antígenos.

\section{INTRODUÇÃO}

Anaplasmose bovina é uma doença com grande importância nas regiões tropicais e subtropicais do mundo por determinar perdas econômicas devido à mortalidade, redução da produtividade dos rebanhos e custos com tratamentos (Palmer et al. 1986, Kocan et al. 2003). É causada por Anaplasma marginale, uma riquétsia intraeritrocítica obrigatória pertencente à ordem Rickettsiales, que foi recentemente reorganizada em duas famílias Anaplasmataceae e Rickettsiaceae baseada na análise genética de 16S rRNA, groELS e genes que codificam para proteínas de superfície (Dumler et al. 2001).

$\mathrm{O}$ controle de $A$. marginale requer além de uma vacina eficiente uma acurada identificação de bovinos portadores (Andrade et al. 2004). Os métodos de detecção disponíveis atualmente baseiam-se na identificação de DNA da riquétsia no sangue por PCR, ou na identificação de anticorpos específicos no soro (McGuire et al. 1991, Knowles et al. 1996). Apesar da alta sensibilidade e especificidade dos métodos moleculares, os métodos sorológicos permanecem sendo os mais utilizados (Silva et al. 2006).

Uma variedade de testes sorológicos, como imunofluorescência indireta (IFI), fixação do complemento (Gonzalez et al. 1978), soroaglutinação (Amerault \& Roby 1968), radioimunoensaio (Schuntner \& Leatch 1988), e ensaios de imunoadsorção enzimática (ELISA) (Thoen et al. 1980), têm sido desenvolvidos para detectar anticorpos para $A$. marginale em bovinos. Dentre estes, o ELISA é o teste mais aplicado devido a sua versatilidade e praticidade (Thoen et al. 1980, Winkler et al. 1987, Duzgun et al. 1988, Nielsen et al. 1996).

Alguns ELISAs para o diagnóstico de $A$. marginale utilizam como antígeno lisado de corpúsculos iniciais da riquétsia parcialmente purificados de eritrócitos bovinos infectados (Barry et al. 1986, Madruga et al. 2000). No entanto, esses ensaios apresentam uma especificidade reduzida devido a reações falso positivas provocadas pela combinação de anticorpos anti-eritrócitos e proteínas eritrocíticas que possam estar contaminando o antígeno (Knowles et al. 1996). Por isso, nos últimos anos, com o auxílio das técnicas de DNA recombinante, a melhoria no diagnóstico sorológico de $A$. marginale focou-se na identificação e produção de proteínas de superfície da riquétsia que pudessem ser utilizadas como antígenos. Recentemente, algumas dessas proteínas foram produzidas e avaliadas como antígenos em ELISAs, MSP1a e MSP2 (Araújo et al. 2005), MSP5 (Torioni de Echaide et al. 1998, Silva et al. 2006, Melo et al. 2007), todas apresentado bons níveis de sensibilidade e especificidade. No entanto, esse grande número de antígenos disponíveis atualmente tem levantado algumas questões relativas à qual antígeno utilizar e qual deles apresenta um melhor desempenho no diagnóstico de $A$. marginale em nível de campo. Essas questões infelizmente não puderam ser respondidas com base apenas na literatura, devido a diferenças nas metodologias de avaliação dos antígenos, que dificultam a comparação entre eles. Por isso esse trabalho teve como objetivo, além de padronizar um ELISA baseado em um coquetel de antígenos recombinantes, comparar o seu desempenho com o de vários antígenos para o diagnóstico de $A$. marginale em bovinos.

\section{MATERIAL E MÉTODOS}

Os ELISAs baseados em lisado de corpúsculos iniciais de Anaplasma marginale $(\mathrm{Cl}), \mathrm{MSP} 1 \mathrm{a}$ e MSP2, e MSP5, foram realizados conforme descrito em Madruga et al. (2000), Araújo et al. (2005) e Melo et al. (2007), respectivamente.

Para a padronização do ELISA baseado em um coquetel de proteínas recombinantes (MIX), diluições ótimas dos antígenos, soros, conjugado e tampões utilizados no ensaio, assim como o tempo de parada da reação enzimática, foram avaliados com seis amostras de soros de bovinos negativos e seis positivos para A. marginale por PCR para msp5.

Após determinação dos parâmetros ótimos, microplacas ${ }^{7}$ foram adsorvidas com as proteínas recombinantes MSP5, MSP1a, e MSP2 (10,4ng, 6ng e 6,4ng/poço, respectivamente) diluídas em tampão Dulbelcco's pH 7,2 (DPBS) e adicionados $100 \mu \mathrm{l} /$ poço. As placas foram incubadas por 1 hora a $37^{\circ} \mathrm{C}$, e ao final desse período foram lavadas cinco vezes com Phosphate buffered saline (PBS) contendo 0,1\% Tween 20 (PBST) e bloqueadas com PBST $+5 \%$ de leite desnatado $(100 \mu \mathrm{l} /$ poço) por 1 hora a $37^{\circ} \mathrm{C}$. Em seguida foram lavadas mais uma vez, conforme descrito anteriormente, e os soros controles e testes adi-

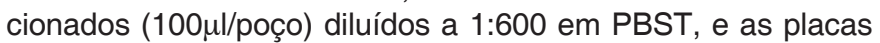
novamente incubadas por 1 hora a $37^{\circ} \mathrm{C}$. Ao final desse período uma nova etapa de lavagem foi realizada e o conjugado anti-IgG bovino/peroxidase ${ }^{8}$ adicionado (100 $\mu \mathrm{l} /$ poço) diluído 1:10.000 em PBST. Após incubação por 30 minutos a $37^{\circ} \mathrm{C}$, as placas foram lavadas e reveladas com Fast-OPD ${ }^{9}$ conforme instruções do fabricante. Após cinco minutos as reações foram paradas com $\mathrm{HCl} 3 \mathrm{~N}(50 \mu \mathrm{l} / \mathrm{poço})$, e as densidades ópticas (DO) obtidas em espectrofotômetro para microplacas ${ }^{10}$, com comprimento de onda de 490nm.

A linha de corte foi estabelecida para cada placa conforme metodologia descrita em Frey et al. (1998), utilizando-se 10 soros controles negativos e um nível de confiança de 99,0\%.

\footnotetext{
${ }^{7}$ Costar $3590 \AA$, Corning Incorporated - Life Sciences, 900 Chelmsford Street, Lowell, Massachusetts, USA.

${ }^{8}$ Anti-IgG bovino/peroxidase, Sigma-Aldrich, 3050 Spruce Street, Saint Louis, Missouri, USA.

9 Fast OPD®, Sigma-Aldrich, 3050 Spruce Street, Saint Louis, Missouri, USA.

${ }^{10}$ Microplate Reader EL-800®, Bio Tek Instruments, P.O. Box 998, Highland Park, Winooski, Vermont, USA.
} 
Para a determinação das sensibilidades e especificidades, foram utilizadas 59 amostras de soro de bovinos positivos a PCR para $m s p 5$, sendo 33 experimentalmente infectados e 26 naturalmente infectados, e 75 amostras de soro de bovinos negativos, também a PCR para msp5. Os cálculos foram realizados em tabelas de contingência 2x2 (Quadro 1) conforme descrito em Coggon et al. (1993).

Para comparar o desempenho dos ELISAs em condições de campo, 360 amostras de soro de bovinos provenientes do Brasil (Estados do Pará $n=80$ e Rio de Janeiro $n=140$ ) e Costa Rica $(n=140)$ foram testadas.

As comparações entre as freqüências de soropositivos para cada antígeno nas três regiões estudadas e as freqüências de resultados discordantes, com base nos resultados de PCR, foram realizadas com o teste de Qui-quadrado com nível de significância de 5\%.

\section{RESULTADOS E DISCUSSÃO}

Das 59 amostras de soro de bovinos positivos para Anaplasma marginale por PCR, $50(84,75 \%)$ apresentaram resultado positivo nos ELISAs com MSP5, MSP1a e MSP2, $54(91,53 \%)$ com MIX e $56(94,92 \%)$ com Cl. Dentre as 75 amostras negativas à PCR, $74(98,66 \%)$ também foram negativas nos ELISAs com MSP5, MSP1a, MSP2 e MIX, e apenas $70(93,33 \%)$ foram negativas com Cl (Quadro 1). As proporções de resultados falsos negativos foram significativamente maiores $(P<0,05)$ nos ELISAs com antígenos recombinantes. Já com $\mathrm{Cl}$, uma maior proporção de resultados falsos positivos $(P<0,05)$ foi observada (Quadro 1). Esses resultados refletiram-se na maior sensibilidade e menor especificidade do ELISA com $\mathrm{Cl}$ em relação aos antígenos recombinantes (Quadro 2).

Em um estudo recente Silva et al. (2006) compararam um ELISA baseado em MSP5 recombinante de $A$. marginale com outro baseado em $\mathrm{Cl}$ e não observaram diferenças significativas entre eles. Esse resultado não corrobo-

Quadro 1. Comparação entre ELISAs e PCR para MSP5 de Anaplasma marginale dos bovinos utilizados como referência para determinação dos parâmetros de sensibilidade e especificidade

\begin{tabular}{ccccc}
\hline & & \multicolumn{3}{c}{ PCR MSP5 } \\
\cline { 3 - 5 } Antígeno & & Positivo & Negativo & Total \\
\hline MSP5 & Positivo & 50 & 1 & 51 \\
& Negativo & 9 & 74 & 83 \\
Total & & 59 & 75 & 134 \\
MSP1a & Positivo & 50 & 1 & 51 \\
& Negativo & 9 & 74 & 83 \\
Total & & 59 & 75 & 134 \\
MSP2 & Positivo & 50 & 1 & 51 \\
& Negativo & 9 & 74 & 83 \\
Total & & 59 & 75 & 134 \\
MIXa & Positivo & 54 & 1 & 55 \\
& Negativo & 5 & 74 & 79 \\
TOTAL & & 59 & 75 & 134 \\
CI & Positivo & 56 & 5 & 61 \\
& Negativo & 3 & 70 & 73 \\
TOTAL & & 59 & 75 & 134 \\
\hline
\end{tabular}

a MIX: MSP1a/MSP2/MSP5.

b Cl: Lisado de corpúsculos iniciais de $A$. marginale.
Quadro 2. Parâmetros de sensibilidade e especificidade para ELISAs baseados em diferentes antígenos de Anaplasma marginale

\begin{tabular}{ccc}
\hline Antígeno & Sensibilidade (\%) & Especificidade (\%) \\
\hline MSP5 & 84,75 & 98,67 \\
MSP1a & 84,75 & 98,67 \\
MSP2 & 84,75 & 98,67 \\
MIX & 91,53 & 98,67 \\
Cl & 94,92 & 93,33
\end{tabular}

ra os aqui observados, porém, pode ser justificado devido à utilização da IFI como teste de referência. Este problema foi ressaltado também por Melo et al. (2007), justificando a utilização de testes mais sensíveis, como a PCR, como ensaios de referência, sob o risco de superestimar os parâmetros de sensibilidade e especificidade dos testes que estão sendo padronizados. Apesar disso, a IFI foi bastante utilizada como teste de referência no desenvolvimento de novos ELISAs para o diagnóstico de $A$. marginale, resultando em sensibilidades tão altas quanto $100 \%$, observada por Madruga et al. (2000) em ELISA com Cl, e $99 \%$, observada por Araújo et al. (2005) em ELISAs baseados em MSP1a e MSP2 recombinantes.

Melo et al. (2007), também observaram parâmetros de sensibilidade $(96,97 \%)$ e especificidade $(100 \%)$, em um ELISA baseado em MSP5 recombinante truncada, superiores aos observados aqui. Nesse caso, uma possível explicação seria a utilização apenas de soros provenientes de bovinos experimentalmente infectados e bovinos mantidos em isolamento como amostras de referência para a determinação desses parâmetros. Isso poderia superestimar tanto a sensibilidade quanto a especificidade do teste. Uma vez que os protocolos de infecção experimental por $A$. marginale geralmente utilizam inóculos contendo um grande número de riquétsias $\left(10^{10}\right.$ eritrócitos infectados) (Palmer et al. 1988, Gale et al. 1996, Hope et al. 2003), o que leva o animal a desenvolver altos títulos de anticorpos, os quais podem ser detectados por testes de menor sensibilidade. Por outro lado, os animais mantidos em isolamento ficam impossibilitados de contrair outros patógenos sanguíneos, como Babesia bovis, B. bigemina, Anaplasma phagocytophilum e A. bovis, que poderiam induzir à formação de anticorpos, os quais poderiam reagir cruzadamente com os antígenos de $A$. marginale, produzindo consequentemente resultados falsos positivos (Silva et al. 2006, Santos \& Carvalho 2006, Góes et al. 2007).

Apesar de os ELISAs baseados em antígenos recombinantes apresentarem uma maior proporção de resultados falsos negativos, todos apresentaram reação falso positiva. Com relação aos testes que utilizaram MSP5 como antígeno (MSP5 e MIX), isso pode ser facilmente explicado devido ao fato dessa proteína ser conservada entre outras espécies de Anaplasma e Ehrlichia (Ndung'u et al. 1995, Dreher et al. 2005, Alleman et al. 2006), e já existirem relatos de reações sorológicas cruzadas entre MSP5 de A. marginale e A. phagocytophilum em bovinos 
(Dreher et al. 2005). Já com relação ao ELISA com MSP2, apesar de não existirem relatos sobre reações sorológicas cruzadas com outras espécies de Anaplasma, essa proteína apresenta ortólogos em todas as espécies conhecidas do gênero (Palmer et al. 1998, Shkap et al. 2002, Lin et al. 2004, De La Fuente et al. 2005). O mesmo não acontecendo com MSP1a (De La Fuente et al. 2005).

A proporção superior de resultados falsos positivos no ELISA com $\mathrm{Cl}$ em relação aos antígenos recombinantes provavelmente ocorreu devido a reações entre resíduos protéicos de eritrócitos, provenientes do processo de produção do antígeno, com anticorpos anti-eritrocíticos. Apesar do desenvolvimento desses anticorpos (anti-eritrocíticos) serem um processo patológico já bem documentado para alguns hemoprotozoários como Babesia gibsoni em cães (Adachi et al. 1992), Babesia rodhaini e Plasmodium berghei em camundongos (Kanbara et al. 1988), em bovinos apenas recentemente foi confirmado com Babesia bigemina (Góes et al. 2007). Além disso, Madruga et al. (2000) já haviam documentado $6,7 \%$ e 1,4\% de reações sorológicas cruzadas entre $B$. bovis, $B$. bigemina e $\mathrm{Cl}$ de A. marginale. Assim como Silva et al. (2006) observaram $15 \%$ de reações sorológicas cruzadas entre $B$. bovis e $\mathrm{Cl}$ da mesma riquétsia.

Analisando soros de diversas regiões observou-se uma freqüência significativamente maior $(P<0,05)$ de bovinos soropositivos com o $\mathrm{Cl}$ em relação aos antígenos recombinantes (Quadro 3). Com base no exposto até aqui, é provável que parte desses resultados sejam falso positivos, provenientes de reações cruzadas com outras espécies de Anaplasma, Ehrlichia e/ou Babesia.

\begin{tabular}{lcccccc}
$\begin{array}{c}\text { Quadro 3. Número de bovinos soropositivos nos ELISAs } \\
\text { com diferentes antígenos de Anaplasma marginale } \\
\text { provenientes do Brasil e Costa Rica }\end{array}$ \\
\begin{tabular}{lccccccc}
\multicolumn{6}{c}{} \\
(nSP5
\end{tabular} & MSP1a & MSP2 & MIX & $\mathrm{Cl}$ \\
\hline Costa Rica & 140 & 16 & 20 & 18 & 17 & 48 \\
Pará & 80 & 59 & 59 & 60 & 60 & 60 \\
Rio de Janeiro & 140 & 43 & 38 & 48 & 54 & 69 \\
Total & 360 & $118 \mathrm{a}$ & $117 \mathrm{a}$ & $126 \mathrm{a}$ & $131 \mathrm{a}$ & $177 \mathrm{~b}$
\end{tabular}

Letras diferentes na mesma linha indicam diferença significativa $(P<0,05)$ pelo teste $\chi^{2}$.

Outro ponto importante nesse trabalho foi a padronização de um ELISA utilizando como antígeno um coquetel de proteínas recombinantes. A hipótese inicial era de que uma maior variedade de epítopos resultaria em um aumento significativo da sensibilidade do teste, conforme observado por Bradley et al. (1993) para Onchocerca volvulus. Porém, o mesmo não foi observado para $A$. marginale. Uma possível explicação para tal fato é que já sendo antígenos de alto desempenho, um aumento significativo nos parâmetros de sensibilidade e especificidade só seria possível de ser observado analisando-se um número excepcionalmente grande de amostras, o que tornaria o trabalho inviável economicamente (Luiz \& Magnanini 2000).
Finalmente, embora mais sensível, o ELISA com antígeno bruto apresentou uma especificidade inferior aos antígenos recombinantes, além de ter um processo de produção mais laborioso e com sérias implicações éticas, uma vez que depende de animais experimentalmente infectados. Além disso, como se pôde observar neste trabalho, a utilização de testes de referência mais sensíveis, assim como a utilização de animais a campo como unidades experimentais, é de fundamental importância para que os parâmetros dos novos ensaios sejam os mais próximos da realidade.

Agradecimentos.- Ao Conselho Nacional de Desenvolvimento Científico e Tecnológico (CNPq).

\section{REFERÊNCIAS}

Adachi K., Yoshimoto A., Hasegawa T., Shimizu T., Goto Y. \& Makimura S. 1992. Anti-erytrocyte membrane antibodies detected in sera of dogs naturally infected with Babesia gibsoni. J. Vet. Med. Sci. 54:10811084.

Alleman A.R., Barbet A.F., Sorenson H.L., Strik N.I., Wamsley H.L., Wong S.J., Chandrashaker R., Gaschen F.P., Luckschander N. \& Bjoersdorff A. 2006. Cloning an expression of the gene encoding major surface proteins 5 (MSP5) of Anaplasma phagocytophilum and potential application for serodiagnosis. Vet. Clin. Pathol. 35:418-425.

Amerault T.E. \& Roby T.O. 1968. A rapid card agglutination test for bovine anaplasmosis. J. Am. Vet. Med. Assoc. 153:1828-1834.

Andrade G.M., Machado R.Z., Vidotto M.C. \& Vidotto O. 2004. Immunization of bovines using a DNA vaccine (pcDNA3.1/MSP1b) prepared from the Jaboticabal strain of Anaplasma marginale. Ann. N.Y. Acad. Sci. 1026:257-266.

Araújo F.R., Melo V.S.P., Ramos C.A.N., Madruga C.R., Soares C.O., Kessler R.H., Almeida N.F., Araújo G.S., Torres Jr R.A.A., Fragoso S.P., Arauco P.R.C., Bacanelli G., Oliveira M.B. \& Santos L.R. 2005. Development of enzyme-linked immunoadsorbent assays based on recombinant MSP1a and MSP2 of Anaplasma marginale. Mem. Inst. Oswaldo Cruz 100:765-769.

Barry D.N., Parker R.J., De Vos A.J., Dunster P. \& Rodwell B.J. 1986. A microplate enzyme linked immunosorbent assay for mensuring antibody to Anaplasma marginale in cattle serum. Aust. Vet. J. 63:7679.

Bradley J.E., Trenholme K.R., Gillespie A.J., Guderian R., Titanji V., Hong Y. \& McReynolds L. 1993. A sensitive serodiagnostic test for Onchocerciasis using a cocktail of recombinant antigens. Am. J. Trop. Med. Hyg. 48:198-204.

Coggon T., Rose G. \& Barker D.J. 1993. Measurement, error and bias, p.20-25. In: Coggon T., Rose G. \& Barker D.J. (Eds), Epidemiology for the Uninitiated. Vol.3. BJM Publishing Group, London.

De La Fuente J., Lew A., Lutz H., Meli M.L., Hofmann-Lehmann R., Shkap V., Molad T., Mangold A.J., Almazán C., Narajo V., Gortázar C., Torina A., Caracappa S., García-Pérez A.L., Barral M., Oporto B., Ceci L., Carelli G., Blouin E.F. \& Kocan K.M. 2005. Genetic diversity of Anaplasma species major surface proteins and implications for anaplasmosis serodiagnosis and vaccine development. Anim. Health Res. Rev. 6:75-89.

Dreher U.M., Fuente J., Hofmann-Lehmann R., Meli M.L., Pusterla N., Kocan K.M., Woldehiwet Z., Braun U. \& Regula G. 2005. Serologic cross-reactivity between Anaplasma marginale and Anaplasma phagocytophilum. Clin. Diagn. Lab. Immunol. 12:1177-1183.

Dumler J.S., Barbet A.F., Bekker C.P., Dasch G.A., Palmer G.H., Ray S.C., Rikihisa Y. \& Rurangirwa F.R. 2001. Reorganization of genera in the families Rickettsiaceae and Anaplasmataceae in the order Rickettsiales: Unification of some species of Ehrlichia with Anaplas- 
ma, Cowdria with Ehrlichia and Ehrlichia with Neorickettsia, descriptions of six new species combinations and designation of Ehrlichia equi and 'HGE agent' as subjective synonyms of Ehrlichia phagocytophilum. Int. J. Syst. Evol. Microbiol. 51:2145-2165.

Duzgun A., Schuntner C.A., Wright I.G., Leatch G. \& Waltisbuhl D.J. 1988. A sensitive ELISA technique for the diagnosis of Anaplasma marginale infections. Vet. Parasitol. 29:1-7.

Frey A., Canzio J. \& Zurakowski D. 1998. A statistically defined endpoint titer determination method for immunoassays. J. Immunol. Meth. 221:35-41.

Gale K.R., Leatch G., De Vos A.J. \& Jorgensen W.K. 1996. Anaplasma marginale: Effect of challenge of cattle with varying doses of infected erythrocytes. Int. J. Parasitol. 26:1417-1426.

Góes T.S., Góes V.S., Ribeiro M.F.B. \& Gontijo C.M. 2007. Bovine babesiosis: Anti-erytrocyte antibodies purification from the sera of naturally infected cattle. Vet. Immunol. Immunopathol. 116:215-218.

Gonzalez E.F., Long R.F. \& Todorovic R.A. 1978. Comparisons of the complement-fixation, indirect fluorescent antibody, and card agglutination tests for the diagnosis of bovine anaplasmosis. Am. J. Vet. Res. 39:1538-1541.

Hope M., Riding G., Menzies M. \& Willadsen P. 2003. A novel antigen from Anaplasma marginale: Characterization expression and preliminary evaluation of the recombinant protein. Vaccine 22:407415.

Kanbara T., Azuma M., Hasegawa K. \& Matsuda H. 1988. Anemia and anti-erytrocyte antibodies developed after repeated injections of sonicated preparations of Plasmodium berguei and Babesia rodhaini. Zentralbl. Bakteriol. Mikrobiol. Hyg. 269:100-108.

Knowles D.P., Torioni de Echaide S., Palmer G., McGuire T., Stiller D. \& McElwain T. 1996. Antibody against an Anaplasma marginale MSP5 epitope common to tick and erythrocyte stages identifies persistently infected cattle. J. Clin. Microbiol. 34:2225-2230.

Kocan K.M., Fuente J., Guglielmone A.A. \& Melendez R.D. 2003. Antigens and alternatives for control of Anaplasma marginale infection in cattle. Clin. Microbiol. Rev. 16:698-712.

Lin Q., Rikihisa Y., Felek S., Wang X., Massung R.F. \& Woldehiwet Z. 2004. Anaplasma phagocytophilum has a functional MSP2 gene that is distinct from p44. Infect. Immun. 72:3883-3889.

Luiz R.R. \& Magnanini M.M.F. 2000. A lógica da determinação do tamanho das amostras em investigações epidemiológicas. Cadernos Saúde Coletiva 8:9-28.

Madruga C.R., Marques A.P., Leal C.R.B., Carvalho C.M.E., Araújo F.R. \& Kessler R.H. 2000. Evaluation of an enzyme-linked immunosorbent assay to detect antibodies against Anaplasma marginale. Pesq. Vet. Bras. 20:109-112.

McGuire T.C., Davis W.C., Brassfield A.L., McElwain T.F. \& Palmer G.H. 1991. Identification of Anaplasma marginale long-term carrier cattle by detection of serum antibody to isolated MSP-3. J. Clin. Microbiol. 29:788-793.

Melo E.S.P., Araújo F.R., Ramos C.A.N., Soares C.O., Rosinha G.M.S.,
Elisei C. \& Madruga C.R. 2007. Elisa com MSP5 recombinante truncada para detecção de anticorpos contra Anaplasma marginale em bovinos. Pesq. Vet. Bras. 7:301-306.

Ndung'u L.W., Aguirre C., Rurangirwa F.R., McElwain T.F., McGuire T.C., Knowles D. \& Palmer G.H. 1995. Detection of Anaplasma ovis infection in goats by major surface protein 5 competitive inhibition enzyme-linked immunosorbent assay. J. Clin. Microbiol. 33:675-679.

Nielsen K., Smith P., Gall D., Torione de Echaide S., Wagner G. \& Dajer A. 1996. Development and validation of an indirect enzyme immunoassay for detection of antibody to Anaplasma marginale in bovine sera. Vet. Parasitol. 67:133-142.

Palmer G.H., Barbet A.F., Kuttler K.L. \& McGuire T.C. 1986. Detection of an Anaplasma marginale common surface protein present in all stages of infection. J. Clin. Microbiol. 23:1078-1083.

Palmer G.H., Oberle S.M., Barbet A.F., Goff W.L., Davis W.C. \& McGuire T.C. 1988. Immunization of cattle with a 36-kilodalton surface protein induces protection against homologous and heterologous Anaplasma marginale challenge. Infect. Immun. 56:1526-1531.

Palmer G.H., Abbott J.R., French D.M. \& McElwain T.F. 1998. Persistence of Anaplasma ovis infection and conservation of msp2 and msp3 multigene families within the genus Anaplasma. Infect. Immun. 66: 6035-6039.

Santos C.F. \& Carvalho C.B. 2006. Primeiro relato de Anaplasma bovis (Donatien et Lestoquard, 1936) Dumler et al. (2001) na microrregião de Campos dos Goytacazes, Estado do Rio de Janeiro, Brasil. Revta Bras. Parasitol. Vet. 15:126-127.

Silva V.M.G., Araújo F.R., Madruga C.R.M., Soares C.O., Kessler R.H., Almeida M.A.O., Fragoso S.P., Santos L.R., Ramos C.A.N., Bacanelli G. \& Torres Júnior R.A.A. 2006. Comparison between indirect enzymelinked immunosorbent assays for Anaplasma marginale antibodies with recombinant major surface protein 5 and initial body antigens. Mem. Inst. Oswaldo Cruz 5:511-516.

Schuntner C.A. \& Leatch G. 1988. Radioimmunoassay for Anaplasma marginale antibodies in cattle. Am. J. Vet. Res. 49:504-507.

Shkap V., Molad T., Brayton K.A., Brown W.C. \& Palmer G.H. 2002. Expression of major surface protein 2 variants with conserved T-cell epitopes in Anaplasma centrale vaccinates. Infect. Immun. 70:642648.

Thoen C.O., Blackburn B., Mills K., Lomme J. \& Hopkins M.P. 1980. Enzyme-linked immunosorbent assay for detecting antibodies in cattle in a herd in which anaplasmosis was diagnosed. J. Clin. Microbiol. 11:499-502.

Torioni de Echaide S., Knowles D.P., McGuire T.C., Palmer G.H., Suarez C.E. \& McElwain T.F. 1998. Detection of cattle naturally infected with Anaplasma marginale in a region of endemicity by nested PCR and a competitive enzyme linked immunosorbent assay using recombinant major surface proteins 5. J. Clin. Microbiol. 36:777-782.

Winkler G.C., Brown G.M. \& Lutz H. 1987. Detection of antibodies on Anaplasma marginale by an improved enzyme-linked immnosorbent assay with sodium dodecyl sulfate-disrupted antigen. J. Clin. Microbiol. 25:633-636. 